\title{
Medical progress, reason and the imagination
}

David Greaves, Martyn Evans Centre for Philosophy and Health Care, University of Wales

Medicine and health care are sometimes thought of as the last bastions of Enlightenment thinking, because they continue to be primarily informed by a nineteenth-century view of scientific rationalism, and hold out endless possibilities for progress, seen as clearly beneficial. There is though nothing in the fabric of Nature to make this "reigning idea" of medical progress either true or inevitable-or even necessarily beneficial were it to be true. Hence, and somewhat in contrast to the objectivist tenor of mainstream Enlightenment thinking, there is a vital and central role for the imagination in the crafting of scientific theory. Ironically, whilst the reality of modern science bears this out, popular conceptions of science-including medical science-continue to cling to the progressivist idea of the perpetual disclosing of new benefit. But as Downie argues in this issue: "It can be maintained that all scientific theories are works of the imagination" and are endlessly provisional, never "true" in the pretheoretical sense.

As such the goods to which theories are harnessed also require our imagination as well as our reason if we are to conceive of them in a sustainable way. Mary Midgley, in a notable new book entitled Science and Poetry, does not deal directly with medicine, but argues powerfully for such an approach to life in general. ${ }^{2}$ She argues that if we are to confront the global problems of the twenty-first century, we will need to restore the wholeness of our lives through bringing together the imaginative resources that unite our entire range of knowledge and practice.

Why though should it appear that medicine and health care are so uniquely involved in this process? One suggestion is that it is because developed societies have come to be organised so that medicine is the repository for the most troubling human questions relating to issues of life, death, illness and disability. The decline of our ultimate values and certainties, formerly provided by religion, has then been largely replaced by an expanded and powerful medical role, but paradoxically one more concerned with a quantitative approach to medical science and management than with human values. As already indicated, however, this position is increas- ingly disputed, and two responses would seem particularly appropriate in relation to medical humanities. The first is the need to re-evaluate the role of medicine, both in practice and in society more generally, recognising that far from being in a sequestered compartment, it actually both reflects societal norms and simultaneously plays an important part in generating them. The second is to acknowledge the need to confront these issues more directly, and in doing so to curtail the unrealistic expectations with which medicine and health care are currently invested. These concerns affect society as a whole, and so will require the involvement of the public (especially those who are patients and lay carers) as well and politicians and health care professionals. We need to return to the old idea of the doctor as Renaissance woman or man, albeit in a modified form, and other health care professionals should also follow this route. This will require a very general appreciation of the arts, social sciences and natural sciences, as the most appropriate basis on which to build an attitude of lifelong learning towards theory and practice in health care. Those engaged in medical humanities should then be in the forefront in this approach, by recognising also the reciprocity of the relationship between society's expectations and the imaginative programmes that drive medical science and practice. Medicine, in informing and-to an extent-supplying or creating these expectations, constitutes a narrative resource for the wider story that we tell about ourselves as humans, a story that has both "natural" and cultural dimensions. Humanity is the author, the object and the subject of medicine; this recognition invites our further inquiry into the role of medicine as one of the cultural "goods" by which we understand and interpret ourselves-an inquiry in which imagination will be as vital as reason.

\section{References}

1 Downie RS. Science and the imagination in the age of reason. fournal of Medical Ethics: Medical Humanities 2001;27: page numbers to come at proof.

2 Midgley M. Science and poetry. London: Routledge, 2001. 